\title{
Article
}

\section{The Numerical Investigation of Structural Strength Assessment of LNG CCS by Sloshing Impacts Based on Multiphase Fluid Model}

\author{
Se-Yun Hwang ${ }^{1}$ (D) and Jang-Hyun Lee ${ }^{2, *(D)}$ \\ 1 Extreme Technology Research Center for Ship and Offshore Platform, INHA University, Incheon 22212, Korea; \\ syhwang@inha.ac.kr \\ 2 Department of Naval Architecture and Ocean Engineering, INHA University, Incheon 22212, Korea \\ * Correspondence: jh_lee@inha.ac.kr; Tel.: +82-32-860-7345
}

Citation: Hwang, S.-Y.; Lee, J.-H. The Numerical Investigation of Structural Strength Assessment of LNG CCS by Sloshing Impacts Based on Multiphase Fluid Model. Appl. Sci. 2021, 11, 7414. https://doi.org/ 10.3390/app11167414

Academic Editors: Julio Marti and Pavel Ryzhakov

Received: 24 June 2021

Accepted: 10 August 2021

Published: 12 August 2021

Publisher's Note: MDPI stays neutral with regard to jurisdictional claims in published maps and institutional affiliations.

Copyright: (c) 2021 by the authors. Licensee MDPI, Basel, Switzerland. This article is an open access article distributed under the terms and conditions of the Creative Commons Attribution (CC BY) license (https:// creativecommons.org/licenses/by/ $4.0 /)$.

\begin{abstract}
Sloshing flows of liquid natural gas (LNG) with multi-phase flow characteristics consisting of liquids and gases can affect the load conditions and structural response of cargo containment systems (CCS). The compressible properties of the sloshing flow can limit the maximum pressure, so a multi-phase fluid model is required to represent the sloshing physics. In this study, we identified a suitable numerical model to simulate the sloshing flow and structural strength evaluation based on the inhomogeneous fluid model. The computational fluid dynamics (CFD) is based on a Eulerian domain model, which is in turn based on the constant volume based finite element method (CVFEM) in a commercial Reynolds-averaged Navier-Stokes CFD code (ANSYS CFX). It includes the interphase momentum transfer between the liquids and gasses. The physics for the sloshing assessment were considered to identify the main aspects of the inhomogeneous multiphase model. For numerical analysis of the sloshing, we conducted a sloshing simulation on the experimental data of the model scale to examine the validity of the results. The velocity of the sloshing flow was extended to the real scale and applied to a local two-way fluid structure interaction (FSI) analysis model. Structural strength evaluation of the LNG CCS by sloshing flow was performed by FSI analysis. Through the example of structural response analysis of Mark III type CCS, the results were discussed and effectiveness of the proposed structural response assessment model by sloshing was reviewed.
\end{abstract}

Keywords: sloshing; fluid impact; multi-phase flow; computational fluid dynamics; fluid structure interaction analysis

\section{Introduction}

Generally, when a containment system filled with fluid cargo is subjected to a disturbance from external motion, a fluid free surface may experience large fluctuating motion. This phenomenon is known as sloshing. When the motion conditions are close to the resonant frequency, the sloshing sometimes creates structural problems since violent sloshing flows create high impact pressures on the cargo containment system (CCS) in marine vessels. Therefore, during the structural design and assessment process of a liquified natural gas (LNG) containment system, it is important that the design procedure should reflect the sloshing load. The sloshing load on the liquid cargo storage tank always affects the structural system. In addition, the sloshing load varies irregularly depending on the loading conditions of the liquid cargo and the operating conditions of the vessel. In studies related with the sloshing loads, several damage cases caused by the sloshing have been identified, especially in partially filled tanks [1-3]. Procedures for sloshing load evaluation are an important part of the LNG CCS design process [4,5]. Therefore, design regulations also present design procedures for the LNG CCS design by sloshing loads [6-8].

In sloshing conditions, the liquid CCS experiences several types of loads that apply impact and kinetic loads to the tank walls and occasionally experience severe loads. In other 
words, hydrodynamic forces acting on the CCS lead to structural failure or fatigue damage. The pressure magnitude and physical characteristics of the hydrodynamic forces influence the structural response of the CCS. Consequently, the sloshing load causes structural problems in the structure of the tank and may be a direct or indirect cause a functional problem of the CCS $[5,9-11]$. The design procedure should consider the technical problem when designing CCS for LNG carriers such as LNG carriers and floating production storage and offloading (FPSO) vessels. Therefore, many researchers have studied the physical characteristics of sloshing flow in a CCSs. Classification societies and shipbuilding engineers have conducted research to address the engineering challenges and provided guidelines to evaluate the sloshing load and structural safety of CCSs [6-13].

In the design stage, the structural assessment methods of the LNG CCS are divided into two methods (the comparative and direct evaluation methods) by sloshing loads of LNG ships [12]. The comparative evaluation method is difficult to apply to new design concept LNG cargo holds as the method requires applying design information for an existing verified design LNG CCS to the new ship. The direct evaluation method consists of evaluating the strength of the CCS by the sloshing pressures through either sloshing experiment or numerical analysis for the new ship's LNG tanks and then specifying the sloshing pressure as a design parameter [13]. To evaluate the structural strength of the CCS based on the direct method, the sloshing pressure is first measured in an experiment with model scale. The pressure is then idealized in a form applicable as a design parameter. Then, structural strength evaluations are performed. However, in the direct procedure it is difficult to investigate the hydro-elasticity effect of the sloshing pressure since the time series history of the sloshing impact loads is simplified into an idealized triangular form. In addition, it is especially difficult to consider the interaction between fluid impact and the behavior of the fluid due to deformation of the cargo hold since the idealized structural analysis method obtains the sloshing pressure first and then simplifies the structural analysis. When applying a model test, the structural strength evaluation method generally estimates the load at real scale by using a scale law since it is not possible to obtain a pressure history directly measured at the actual scale [13,14].

To evaluate the structural strength of the LNG CCS subjected to sloshing loads, it is necessary to make a reasonable evaluation that reflects the hydro-elasticity effect and apply it in a method appropriate to the structural strength evaluation through a sloshing fluid structure interaction (FSI) analysis method $[15,16]$. FSI analysis is a method that can analyze the sloshing phenomenon by simultaneously analyzing fluid flow and structural deformation. However, it is difficult to obtain both solution convergence and result accuracy since the fluid flow analysis depends heavily on the numerical calculation method [13,17]. Therefore, various studies have been conducted and published using FSI analysis to simulate fluid flow during sloshing impact. Chen and Nokes analyzed nonlinear and viscous flow of sloshing in a rectangular tank using the finite difference method (FDM) [18]. The FDM was also used for sloshing flow in a 3D rectangular tank subjected to harmonic excitation [19]. Kim numerically studied sloshing flows with impact loads in 2D and 3D liquid containers by FDM to analyze the characteristics of sloshing impact loads [10]. The finite element method was used to calculate the governing equation of fluid flow in a differential form assuming a fluid continuum model for analyzing the sloshing impact in a partially filled tank under irregular excitation [20]. However, most of the effort undertaken to assess sloshing fluid flow was focused on simple fluid models, such as continuous fluid or homogeneous multi-phase models, due to relatively low computational costs and excellent numerical stability [21,22].

The compressibility and multiphase properties of fluids should be taken into account when modeling the sloshing flow, as fluid is mixed with gases and liquids in the event of a sloshing impact. Godderidge et al. suggested that an inhomogeneous model is suitable as a multi-phase model of sloshing flow and compared a homogeneous and an inhomogeneous multi-phase model for sloshing flow in a rectangular tank subjected to harmonic excitation [23]. As a time-averaged equation of fluid flow motion, the Reynolds- 
averaged Navier-Stokes (RANS) equation is widely used to simulate sloshing flows. The RANS equation can be applied with approximations based on information of the properties of sloshing flow and turbulence properties to provide approximate time-averaged solutions to the Navier-Stokes equations. This method is used to solve multi-phase fluid flows in most commercial CFD codes, ANSYS CFX, with various usage of volume of fluid (VOF) approaches [24].

The present study is designed to evaluate the effect of sloshing impact on structural strength. The method for evaluating structural strength is to apply the FSI analysis method and consider the hydro-elastic effect of the sloshing flow. For the FSI analysis method, a fluid impact model of LNG sloshing was created based on VOF approaches and the RANS. The CFD models are based on a Eulerian-Eulerian model using the control volume based finite element method (CVFEM). The inhomogeneous multiphase model included fluid flow and gas entrapment as well as momentum transfer between liquid and gas. To review the suggested multi-phase model and the application of fluid impact simulations, analysis results were compared with experimental results of dam breaking problems presented by $\mathrm{Hu}$ and Kashiwagi, as well as a rectangular sloshing model test $[25,26]$. The validated CFD model, combined with the FSI method, performed a structural strength evaluation of LNG CCS by sloshing impact on the Mark III type CCS model. Finally, we discussed the results of structural response analysis of Mark III type CCS reviewed in this study and investigated the effectiveness of the FSI model on structural response evaluation by the proposed sloshing simulation model.

\section{Numerical Scheme}

The model of sloshing flow requires the consideration of various flow complexities such as the multi-phase (gas/liquid) flow, viscosity, and compressibility of the fluids. Sloshing flow is described by the multi-phase model based on a discretization scheme for RANS CFD problems. The multi-phase model for the sloshing simulation can determine the fluid properties using the volume fraction of each fluid. It is the homogeneous multiphase model which is similar to the VOF approach. However, the relatively increasing computational time approach is an inhomogeneous multi-phase model, which generally uses mass and momentum transfer models to match solutions in separate velocity fields for each fluid at the fluid interface [23]. The homogeneous models are commonly used in sloshing simulations due to their relatively low computational time and excellent numerical stability [23,27]. However, the physics of violent sloshing flows, including breaking fluid flows, steam jams, and compressible fluid flows, can have different consequences than assumptions inherent in the homogeneous models [16,23,26-28]. An inhomogeneous fluid model will be able to calculate a more accurate result because the sloshing impact phenomenon must be accurately reflected in the sloshing strength evaluation process for calculating the structural response of the LNG CCS.

\subsection{Governing Equations}

The RANS CFD method with the VOF model includes pressure boundary conditions on the free surface of fluid flow [24]. Assuming a homogeneous multi-phase flow model using the VOF method allows one to ignore the relative motion between phases.

With the homogeneous multiphase flow assumed in most implementations of the VOF method, it can ignore the relative motion between the phases. The interface momentum transfer and velocity fields are also resolved using only one set of momentum conservation equations in both phases. The governing equation for homogeneous flows uses the following mass and momentum conservation equations:

$$
\begin{gathered}
\frac{\partial \rho}{\partial t}+\frac{\partial}{\partial x_{i}}\left(\rho u_{i}\right)=0 \\
\frac{\partial}{\partial t}\left(\rho u_{i}\right)+\frac{\partial}{\partial x_{j}}\left(\rho u_{i} u_{j}\right)=-\frac{\partial p}{\partial x_{i}}+\mu \frac{\partial^{2} u_{i}}{\partial x_{j} \partial x_{j}}+b_{i}
\end{gathered}
$$


where $b_{i}$ is the external body force, $p$ is pressure, and $u_{i}$ and $x_{i}$ are the Cartesian velocity and coordinate tensors. Only one momentum conservation equation is used for both fluids. The homogenous approach uses a dynamic viscosity $(\mu)$ and density $(\rho)$ of the fluid mixture calculated using the volume fraction $\left(r_{k}\right)$ with the constraint $\sum r_{k}=1$, as expressed in Equations (3) and (4).

$$
\begin{aligned}
& \rho=\sum \rho_{k} r_{k} \\
& \mu=\sum \mu_{k} r_{k}
\end{aligned}
$$

For inhomogeneous fluid flow, the interfacial momentum and mass transfer is directly dependent on the interface surface area between the two phases. It is characterized by the interaction area per unit volume between two phases. Therefore, the interface momentum transfer and the velocity field are solved for both phases. An inhomogeneous viscous compressible multiphase flow with two phases $(\alpha$ and $\beta$ ) can be described by Equations (5) and (6).

$$
\begin{gathered}
\frac{\partial}{\partial t}\left(r_{k} \rho_{k}\right)+\frac{\partial}{\partial x_{i}}\left(r_{k} \rho_{k} u_{i}\right)=m+\Gamma_{\alpha \beta} \\
\frac{\partial}{\partial t}\left(r_{k} \rho_{k} u_{i}\right)+\frac{\partial}{\partial x_{j}}\left(r_{k} \rho_{k} u_{i} u_{j}\right)=-r_{k} \frac{\partial p}{\partial x_{i}}+\frac{\partial}{\partial x_{j}}\left(r_{k} \mu_{k} \frac{\partial u_{i}}{\partial x_{j}}+\frac{\partial u_{j}}{\partial x_{i}}\right)+M^{\Gamma_{\alpha \beta}}+M^{r_{k}}+b_{i}
\end{gathered}
$$

where $\Gamma_{\alpha \beta}$ is the mass transfer between phases, $m$ is the mass source expressed in Equation (7), $M^{r_{k}}$ is the force on the interface caused by the presence of phase $\beta$ as expressed in Equation (8), and $M^{\Gamma_{\alpha \beta}}$ is interphase momentum transfer caused by mass transfer. The interface momentum transfer $\left(M^{r_{k}}\right)$ needs to be taken into account as it ties the fluid velocity fields. This term may be modelled by drag force $\left(M^{D}\right)$ as the dominant force acting on the fluid interface in the sloshing problem, as described in Equation (8).

$$
\begin{gathered}
\Gamma_{\alpha \beta}=\dot{m}_{\alpha \beta} A_{\alpha \beta}=\Gamma_{\alpha \beta}^{+}-\Gamma_{\beta \alpha}^{-} \\
M^{r_{k}} \approx M^{D}
\end{gathered}
$$

where, the interphase drag force $\left(M^{D}\right)$ is expressed using the drag coefficient, as follows:

$$
C_{D}=\frac{D}{0.5 \rho\left|u_{\alpha}-u_{\beta}\right|^{2} A}
$$

where $A$ is interfacial area, $D$ is drag, $\rho$ is density, and $\left|u_{\alpha}-u_{\beta}\right|$ is the velocity between the phases $\alpha$ and $\beta$. For the current Newtonian flow regime, a drag coefficient of 0.45 is used [28].

\subsection{Dam Breaking Problem}

In order to review the validity of the multi-phase model by the CVFEM and to examine the application for the fluid impact simulation, the CFD results were examined on the experimental results of the dam breaking problem presented by $\mathrm{Hu}$ and Kashiwagi [26]. The experiment measured the fluid collision pressure of the sensor installed at point $\mathrm{A}$ of the right wall as a $120 \mathrm{~mm} \times 680 \mathrm{~mm}$ water column was moved by gravity as shown in Figure 1a. The experiment was repeated for a total of eight times, and the measured pressure history was the average value of the pressures as shown in Figure 2a. To verify the multiphase fluid model, a 2D numerical model with symmetric conditions was applied, as shown in Figure 1b. The fluid domain consists of multi-phase flow of air and water, which is defined as a compressible fluid and incompressible fluid in a dispersed form so that water can be mixed with air at the moment of impact. Furthermore, to improve the convergence of the numerical model, the upper side of the domain was defined to allow air to flow of the fluid domain by applying an opening condition with a reference pressure of " 0 ". The simulation results show that the fluid flow was caused by gravity, as a result, the fluid impact occurred to the right wall. 


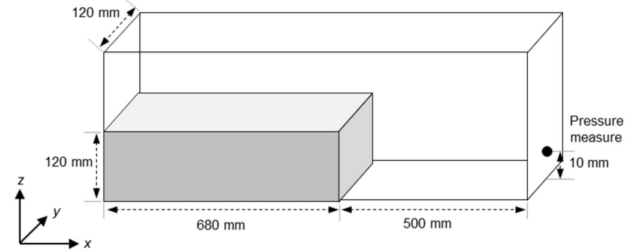

(a)

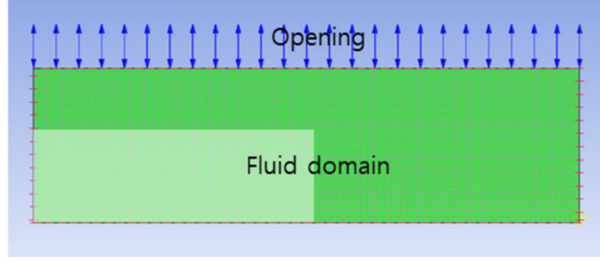

(b)

Figure 1. Configuration of experiment (a) and CFD model (b) for dam-breaking problem [27].

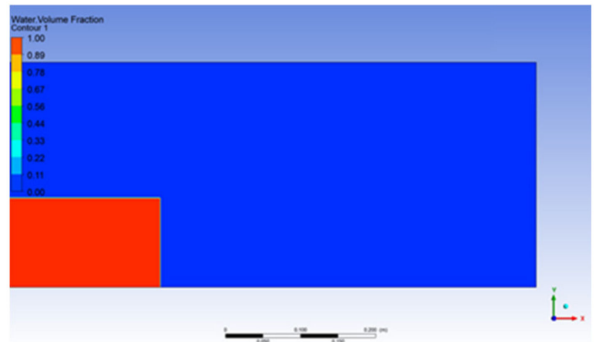

(a)

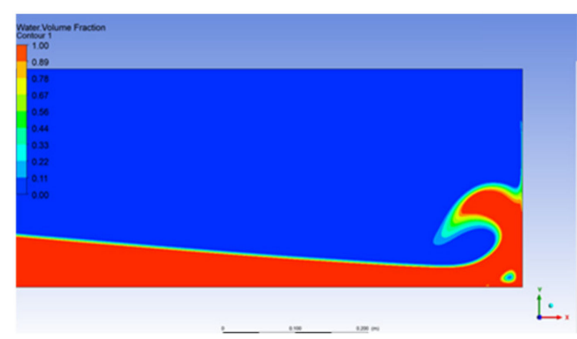

(c)

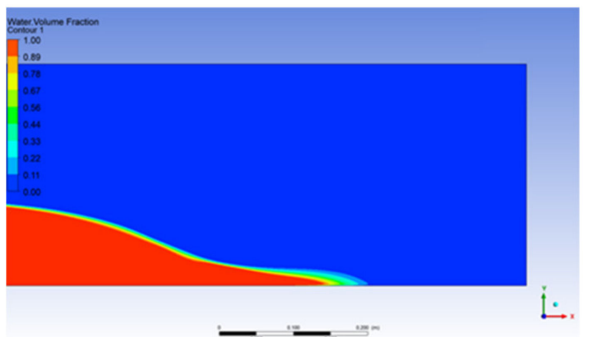

(b)

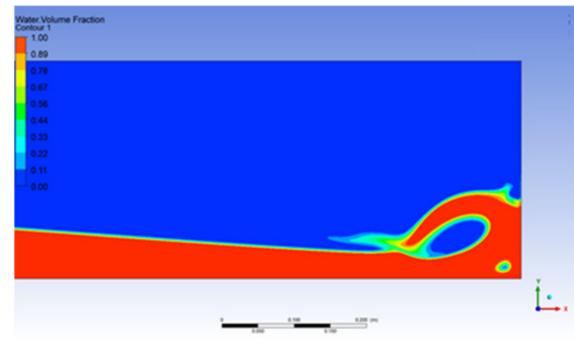

(d)

Figure 2. Free surface history of dam breaking problem based on water volume fraction: (a) $0.0 \mathrm{~s}$; (b) $0.2 \mathrm{~s}$; (c) $0.7 \mathrm{~s}$; (d) $0.9 \mathrm{~s}$.

The experiment was repeated a total of eight times and the measured pressure history produced a maximum pressure of approximately 1.4-1.7 kPa [26]. The CFD analysis also generated impact pressure on the right wall, and the max pressure of $1.67 \mathrm{kPa}$ was analyzed as shown in Figure 3. Comparing the experiments with the CFD results, the max impact pressure was calculated similarly, and the generation time (about $0.35 \mathrm{~s}$ ) of the max pressure and the pressure history were calculated similarly. The results comparison shows that the inhomogeneous multiphase model presented in this study is suitable for simulating fluid impacts.

\section{Sloshing Simulation}

\subsection{Sloshing Problem}

The proposed numerical analysis approach was applied to the results of small-scale model tests for verification. The model test experiment was carried out under regular sway conditions at 1:50 scale with harmonic sway motion defined by Equation (10). The model test was performed by Daewoo Shipbuilding and Marine Engineering Co., Ltd., (Geoje, South Korea) a South Korean shipyard. Additionally, the measured impact history was measured by Seoul National University. The pressure histories obtained from the CFD model were compared with the experimental sloshing pressure data to evaluate the validity of the proposed numerical analytical model. Figure 4 shows the apparatus used for the small-scale model test. In the model test resonant case, the excitation period is $5.388 \mathrm{rad} / \mathrm{s}$ for the $0.02 \mathrm{~m}$ amplitude sway motion.

$$
Y=\xi \sin (\omega \cdot t)
$$


where $\xi$ is the excitation amplitude and $\omega$ is the excitation frequency ( $\mathrm{rad} / \mathrm{s})$. The excitation frequency is based on the natural frequency of the fluid motion in the tank expressed in Equation (11).

$$
\omega_{n}^{2}=\frac{\pi \cdot g}{L} \cdot \tanh \left(\pi \cdot \frac{h}{L}\right)
$$

where $L$ is length of tank and $h$ is the depth of fluid.

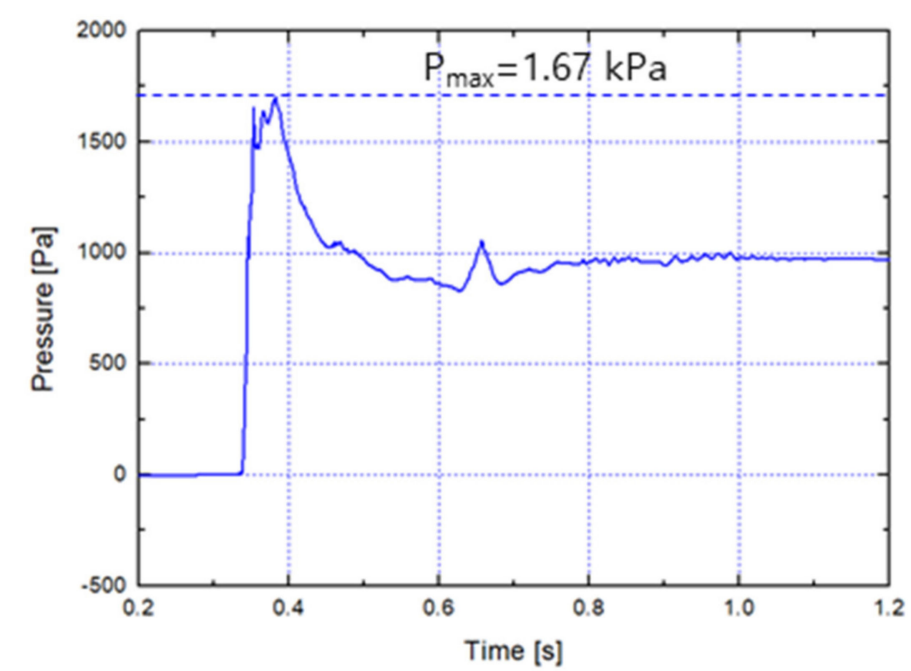

Figure 3. Comparison of pressure history of present study.

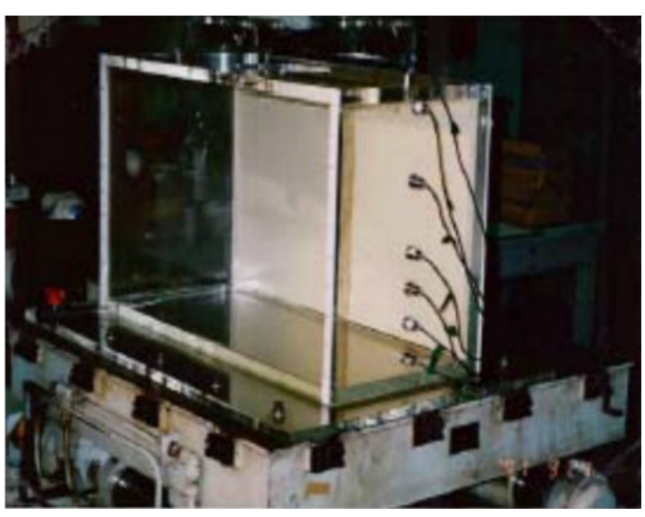

(a)

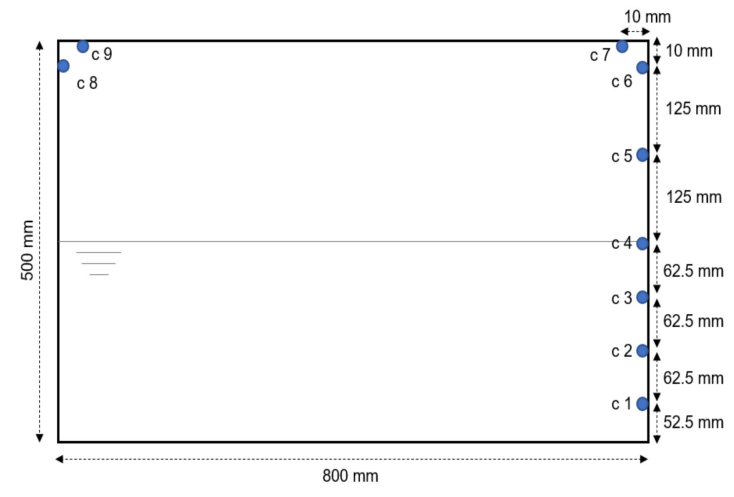

(b)

Figure 4. Experiment apparatus (a) and sensor locations (b) for the sloshing model test.

\subsection{Simulation Model}

A CVFEM method based on the Eulerian-Eulerian model was used to simulate the behavior of the fluid flow during the sloshing model test. An induced sloshing flow in the experimental condition is modelled using ANSYS CFX commercial Navier-Stokes VOF-CFD code [24]. The CFD code converts the governing differential equation to a set of algebraic equations by discretizing the fluid domain using constant volume based finite element method (CVFEM). The experimental conditions applied in this study are 2D experiments with regular sway motion conditions. However, the real experiments have produced in 3D conditions. Therefore, efficient 2D model was considered using 1-layer grid with symmetry conditions. The model test condition with a filling ratio of $50 \%$ of the tank height creates a violent impact in the upper edge under resonance conditions. Therefore, the computational grid for the wall of the tank was divided into small pieces using volume grids as shown in Figure 5. Furthermore, the sloshing model was defined 
using a commercial CFD program (ANSYS CFX) applied with VOF approaches and the RANS. In this work, grid dependency tests were conducted to examine the uncertainty of the sloshing CFD models.

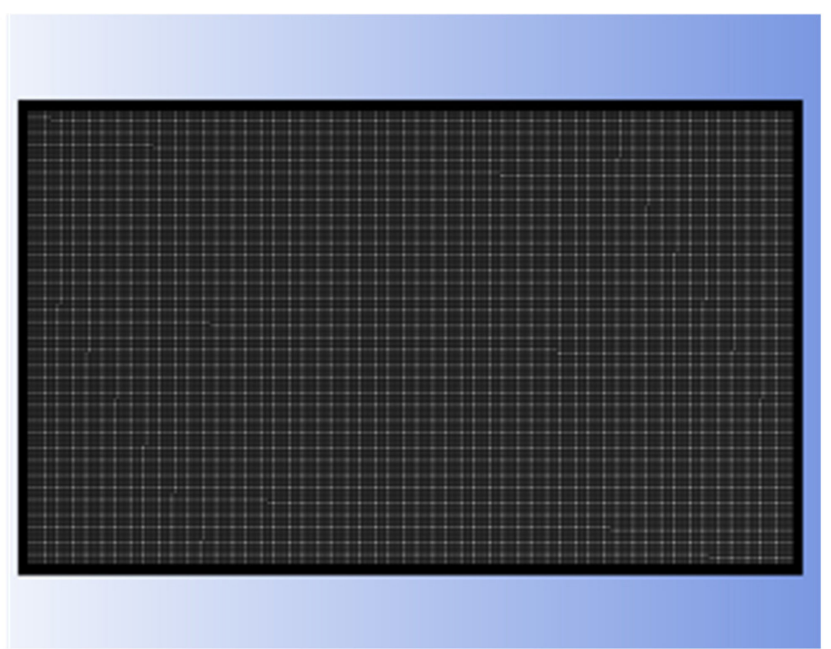

(a)

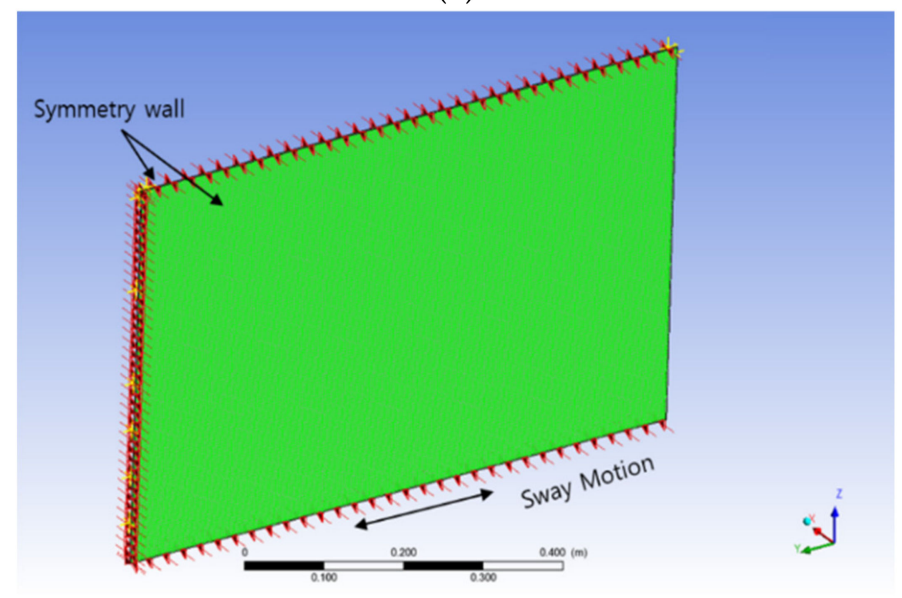

(b)

Figure 5. Computational grid (a) and boundary condition (b) for sloshing model test simulation.

Yang et al. obtained good results under grid conditions 128 by 80 with the same sloshing conditions by CCUP Method [25]. In this study, sensitivity analysis was performed by varying the number of grids under the conditions of 64 by 40,128 by 80 , and 192 by 120 to examine the same conditions in the commercial CFD code. When the simulation time and timestep were selected as $20 \mathrm{~s}$ and $0.001 \mathrm{~s}$ for each condition analysis. The analysis times of each analytical model were approximately $6 \mathrm{~h}, 40 \mathrm{~h}$, and $62 \mathrm{~h}$, respectively, in workstation environments using i7 intel CPUs. The 192 by 120 grid condition was selected by the grid dependency test, and the total of grid of the sloshing CFD model used 23,040 hexahedral elements.

Since the computational domain is completely enclosed, we have set the reference pressure by defining the center in the cell as shown in Figure 6. For evaluation of the proposed model, pressure signals are collected at the same positions as the model test. The atmospheric reference pressure is specified with reference to the center position node in the center of the top wall. The body force approach is applied to simulate tank motion. A standard k-e turbulence model was used in the CFD model. 


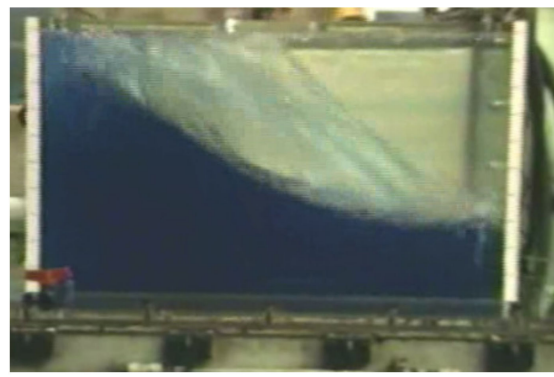

(a)

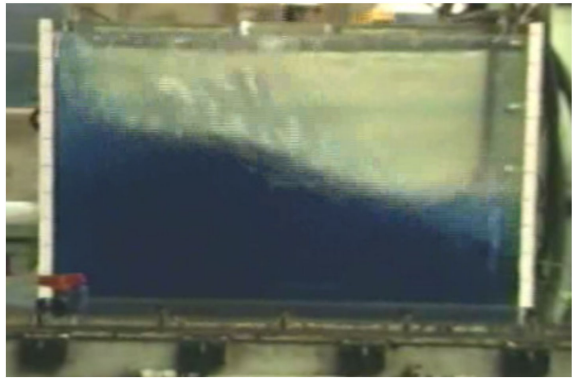

(c)

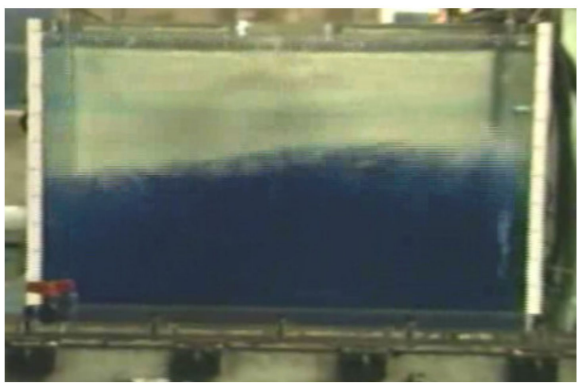

(e)

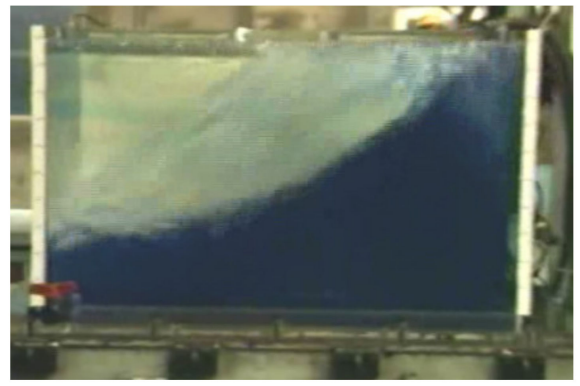

(g)

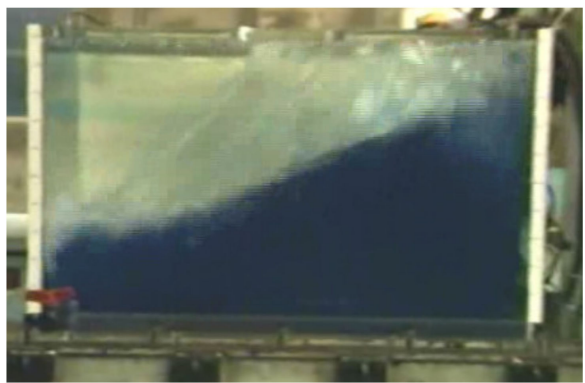

(i)

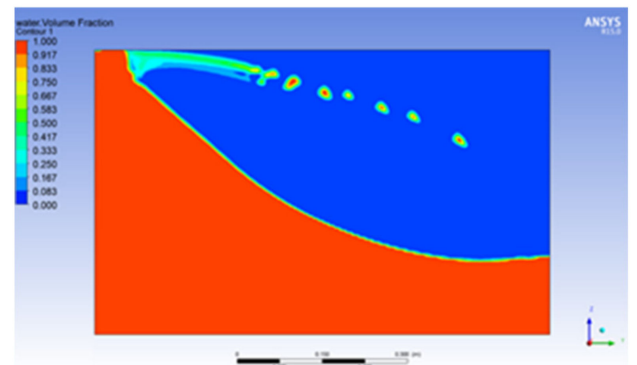

(b)

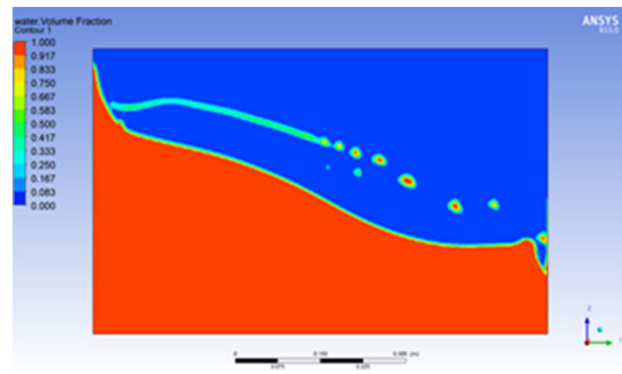

(d)

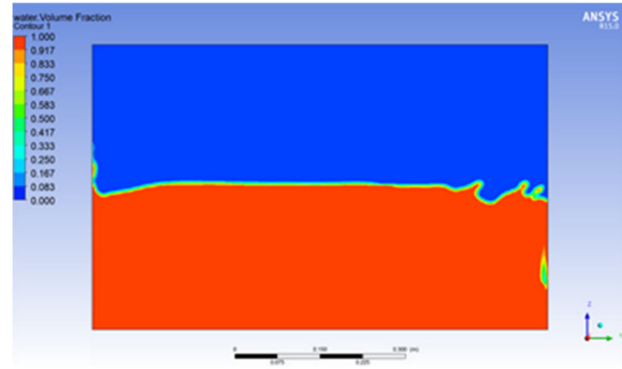

(f)

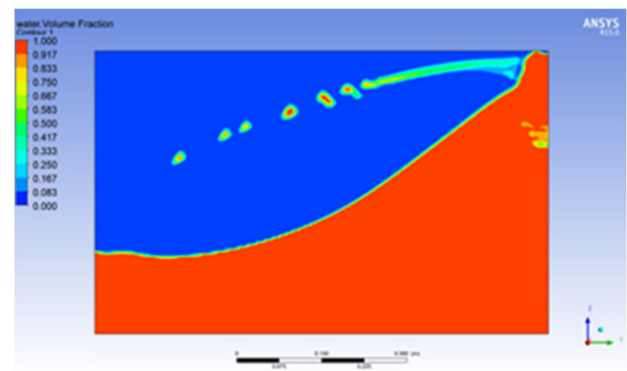

(h)

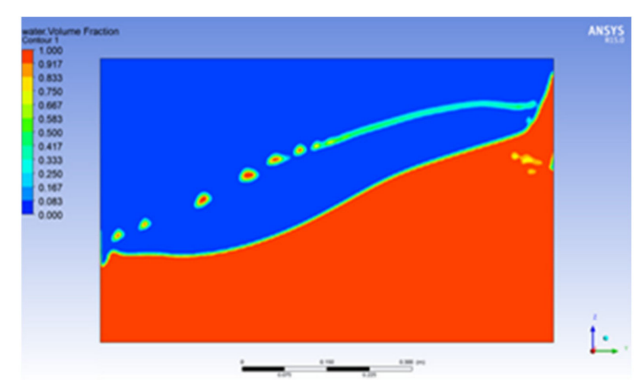

(j)

Figure 6. Comparisons of free surface profiles between model test and CFD: (a) Experiment; (b) CFD; (c) Experiment; (d) CFD; (e) Experiment; (f) CFD; (g) Experiment; (h) CFD; (i) Experiment; (j) CFD. 


\subsection{Simulation Results of Sloshing}

Figure 6 shows the comparison of the behavior of the free surface between the CFD simulation and the model test. When the tank is excited in the resonance state, the liquid is dispersed in the form of water droplets when the liquid collides against the tank wall surface, and an irregular free water surface appears. Furthermore, the proposed CFD model also shows that air flows into the liquid from the wall of the tank when liquid impact occurs, as seen in the experiment, and the air is distributed in a mixed state inside the liquid. Therefore, comparing the behavior of the free water surface with the experiment, the proposed CFD model simulates sloshing shock characteristics well.

\subsection{Pressure History of Sloshing Pressure}

To investigate the validity of the inhomogeneous multiphase flow model, the CFD analysis results were compared with the experimental results. The results were also compared for the conditions of the grid condition considered in the CFD model. The experimental results showed that the hydro pressure was generated at the lower part of the free surface at the $50 \%$ filling ratio, and the sloshing impact pressure was generated at the upper part. Each pressure history was examined in detail. When comparing the results of the hydro pressure history as shown in Figure 7, although some phase differences in pressure history are found due to experimental errors, the cycle of the sloshing pressure is well maintained to confirm that the proposed approach is appropriate for CFD modeling of the sloshing simulation. The phase difference generated at this time is thought to be from the error that occurs since the motion condition applied in the experiment does not exactly match the natural frequency of the model test calculated by Equation (10).
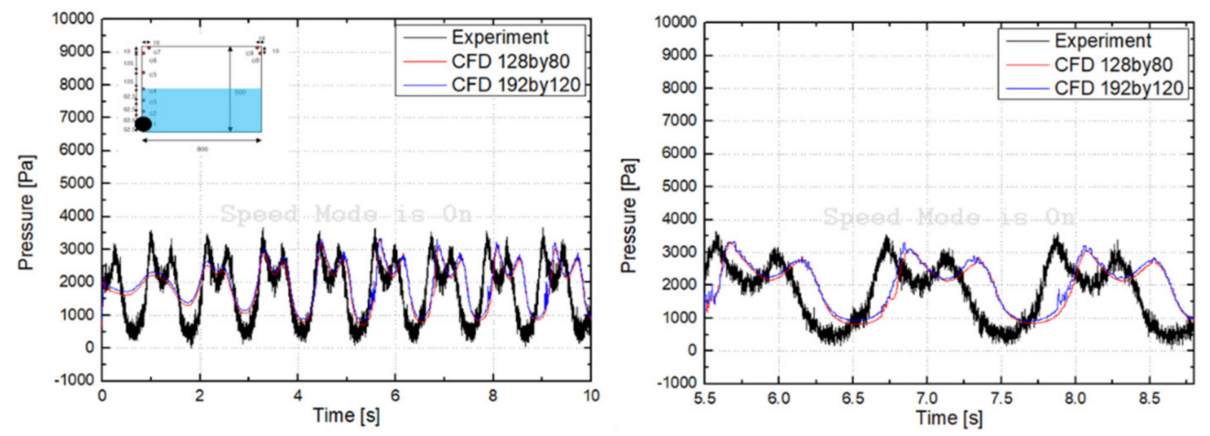

(a)
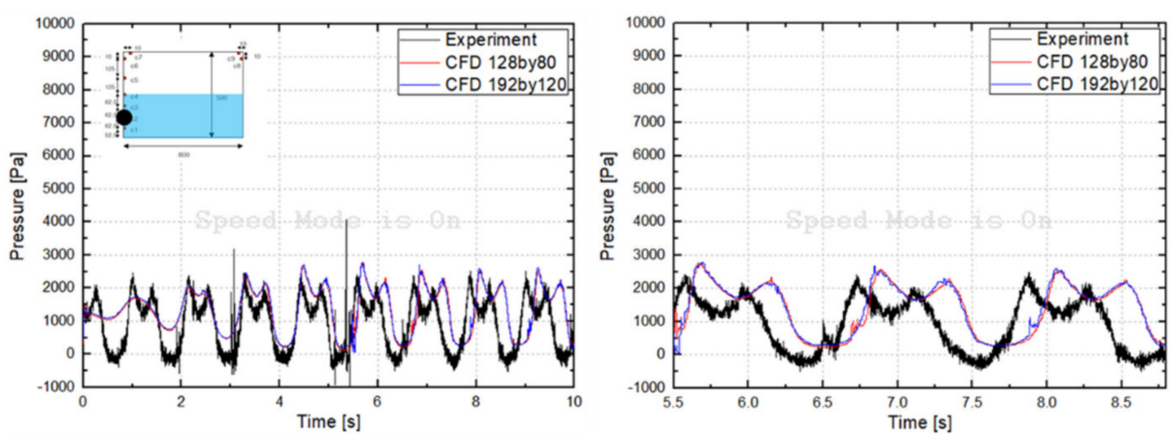

(b)

Figure 7. Comparison of hydro pressure history under the free water surface between experiment and CFD analysis at $\mathrm{C} 1$ sensor (a) and C2 sensor $(\mathbf{b})$.

And the sloshing impact pressure was observed on sensors located above the free surface at the 50\% filling ratio as shown in Figure 8. Although uncertainty in the experiment resulted in some differences in $\mathrm{C} 6$ sensor positions, it was confirmed that the pressure history had similar behavior for certain impact pressures at C7 and C9. In particular, the 
CFD models with a grid of 192 by 120 were found to calculate better behavior of impact pressure than other models. High impact pressures are occurring repeatedly near the top corner of the model test. The results show that the proposed CFD model is appropriate for the sloshing pressure calculation by observing the impact pressure history of the C6, C7 and C9 sensors in Figure 8, which is thought to have the least experimental error. Since the analysis solution estimated the pressure peaks at steady state, the results did not completely match the experimental results at the reference points.
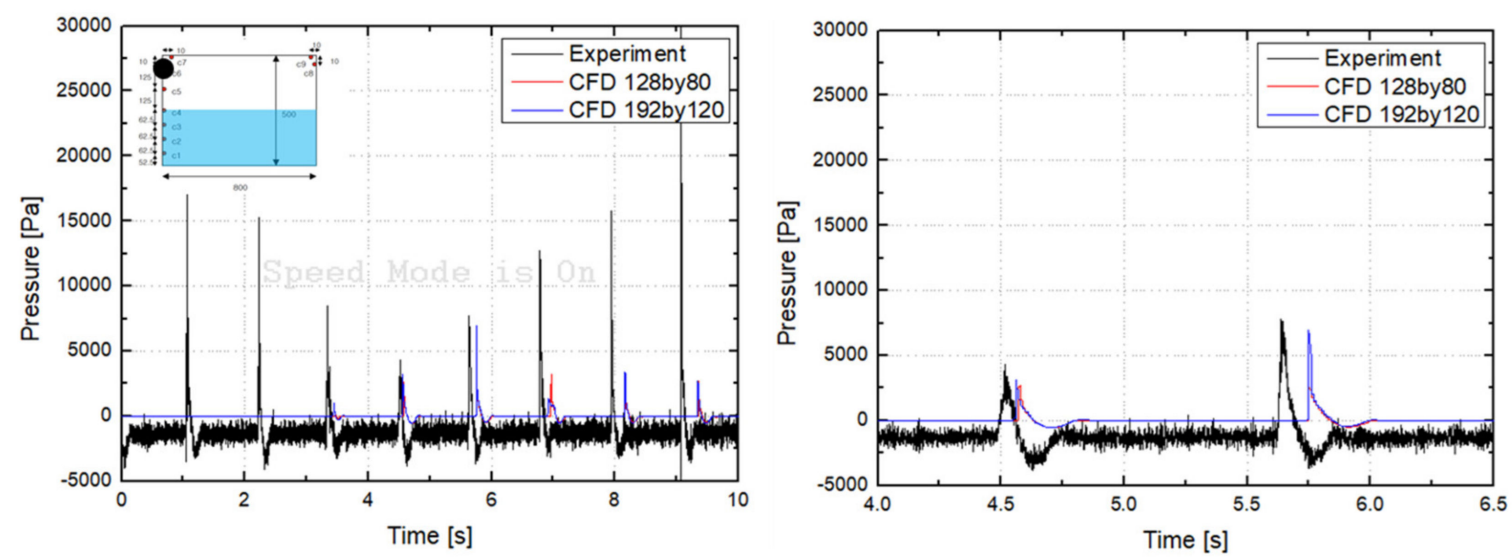

(a) Impact pressure history at C6 sensor
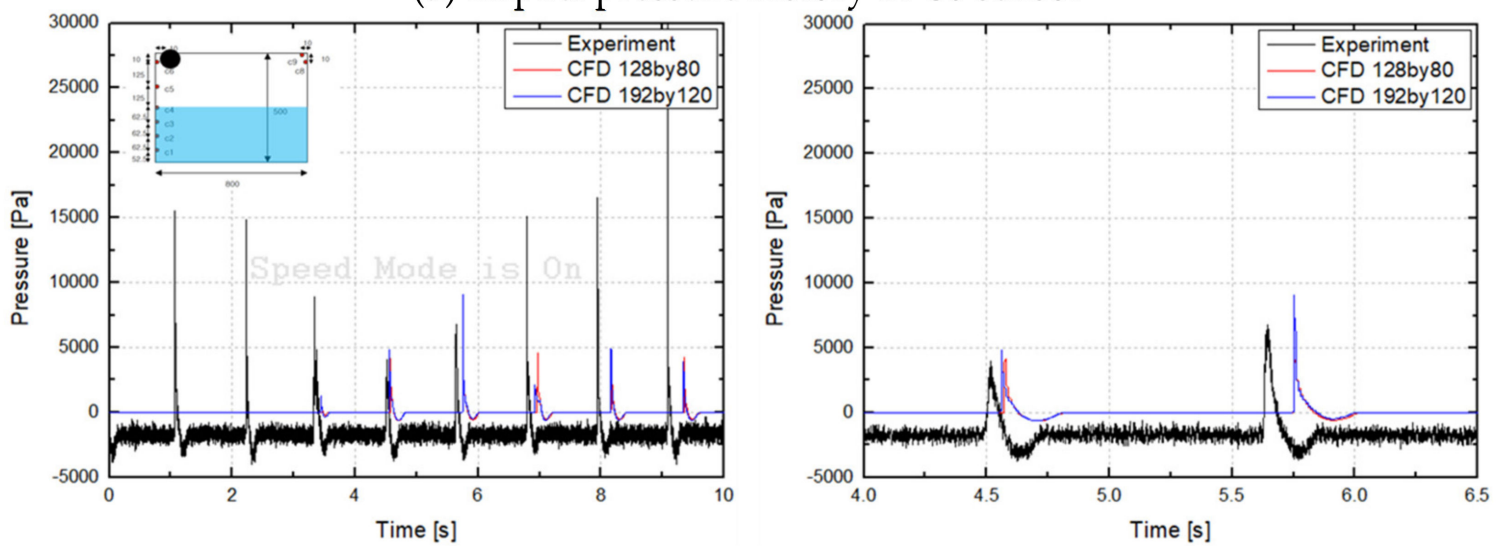

(b) Impact pressure history at C7 sensor
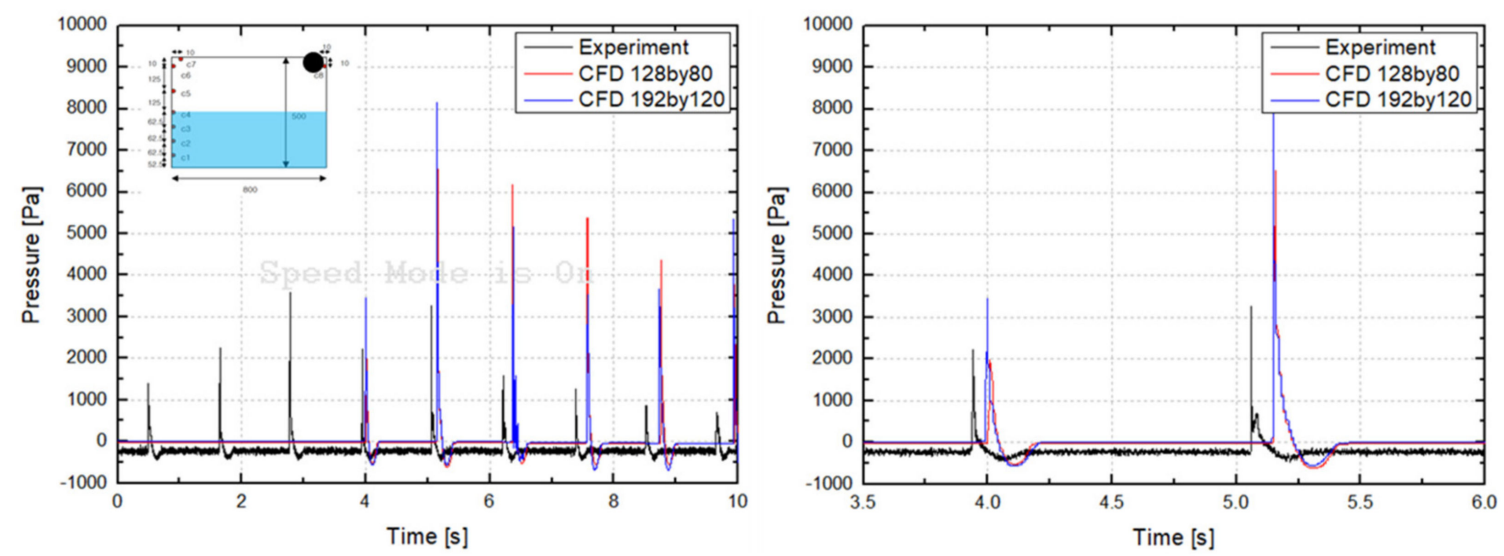

(c) Impact pressure history at C9 sensor

Figure 8. Comparison of impact pressure history between experiment and CFD analysis: at C6 sensor (a); C7 sensor (b); C9 sensor (c). 
In this study, the velocity of induced maximum fluid impact loads calculated from the sloshing CFD analysis is calculated and transferred to the FSI (fluid structure interaction) analysis. Therefore, the CFD analysis determined when the maximum impact load occurred, and a pressure of approximately $9 \mathrm{kPa}$ was calculated at the $\mathrm{C} 7$ sensor location as shown in Figure 9.

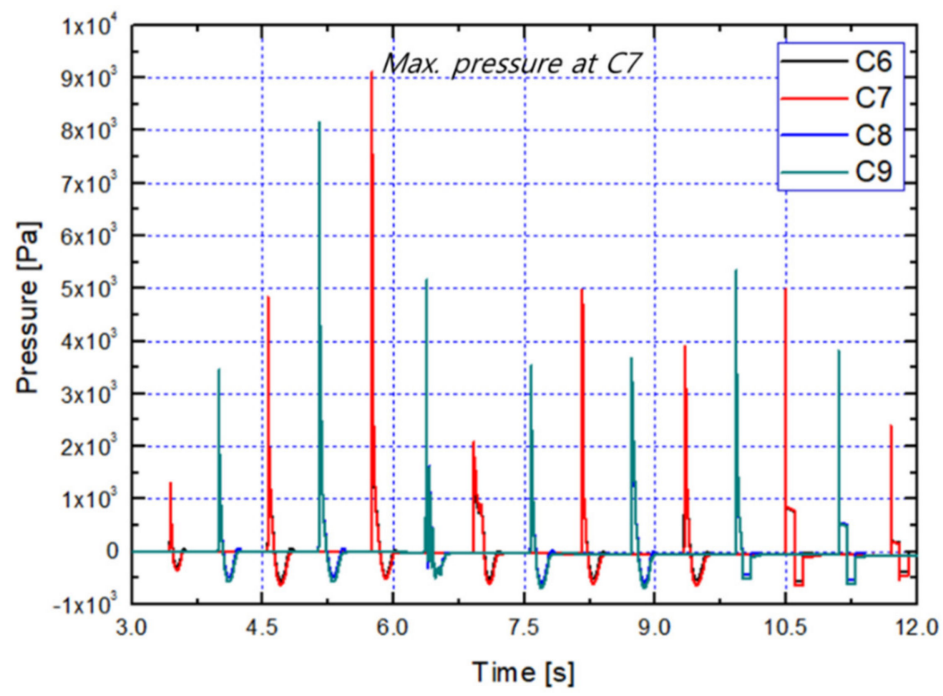

Figure 9. Sloshing pressure history in CFD analysis.

\section{Fluid Structure Interaction Analysis}

To predict the structural response of the LNG CCS to the sloshing fluid impact, the structural response was analyzed using an FSI analysis. However, the FSI analysis method requires a long computation time since it performs the analysis in parallel with the fluid problem and the structural problem at each timestep. Multi-phase fluid flow of LNG and gas compressibility may have a large effect on excited pressures and structural response. Therefore, the coupled approaches are introduced using a localized fluid column model, as shown in Figure 10, as a practical FSI method. This method can simulate the LNG sloshing and efficiently analyze the structural response of LNG CCS. The structural response of the FSI model requires a transient analysis scheme. The structural response was iteratively calculated while the interaction between the motion of the fluid column and the structural deformation was updated at every time increment in the analysis. The FSI method was employed to evaluate the structural strength at real scale for a Mark III CCS. As a result, the analytical results by the FSI model are evaluated to discuss the FSI method for the sloshing assessment.

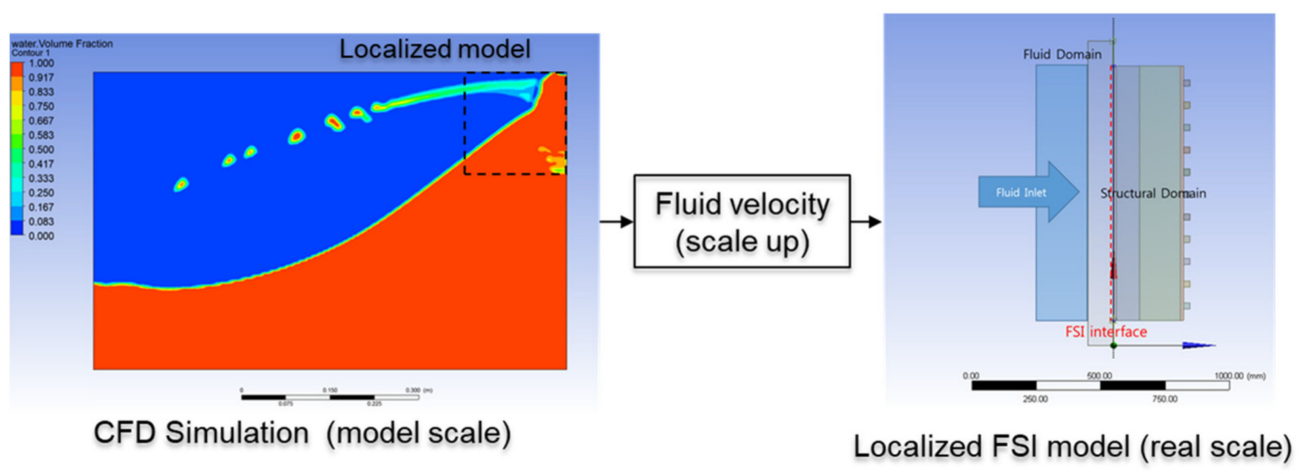

Figure 10. Analysis procedure for structural assessment of CCS. 


\subsection{LNG CCS Model}

A Mark III CCS was selected for structural assessment. The insulation panel of a Mark-III CCS consists of a thin corrugated membrane, plywood, reinforced poly-urethanform (R-PUF), triplex, and mastic, as shown in Figure 11. It also consists of two layers of R-PUF divided by triplex material, and it is attached to the hull by mastic. Since the main interest of this study is to investigate the dynamic response of the R-PUF, plywood, and the highly loaded region around the mastic supports, an insulation system without triplex and membrane is considered for the finite element meshes. Hence, the primary membrane and triplex is ignored for the structural finite element (FE) model.

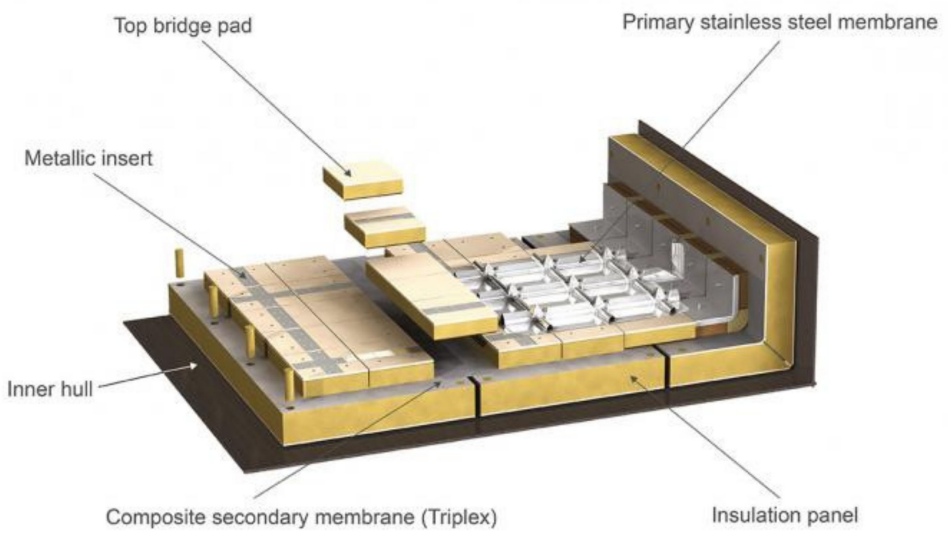

Figure 11. Schematic view of a Mark III type LNG insulation panel [29].

In this study, we will consider the local FSI analysis method proposed. The structural analysis should select a model that matches the CCS used in the sloshing strength evaluation. However, from the viewpoint of examining the methodology of the strength evaluation method presented in this study, a flat CCS model was selected as shown in Figure 12.

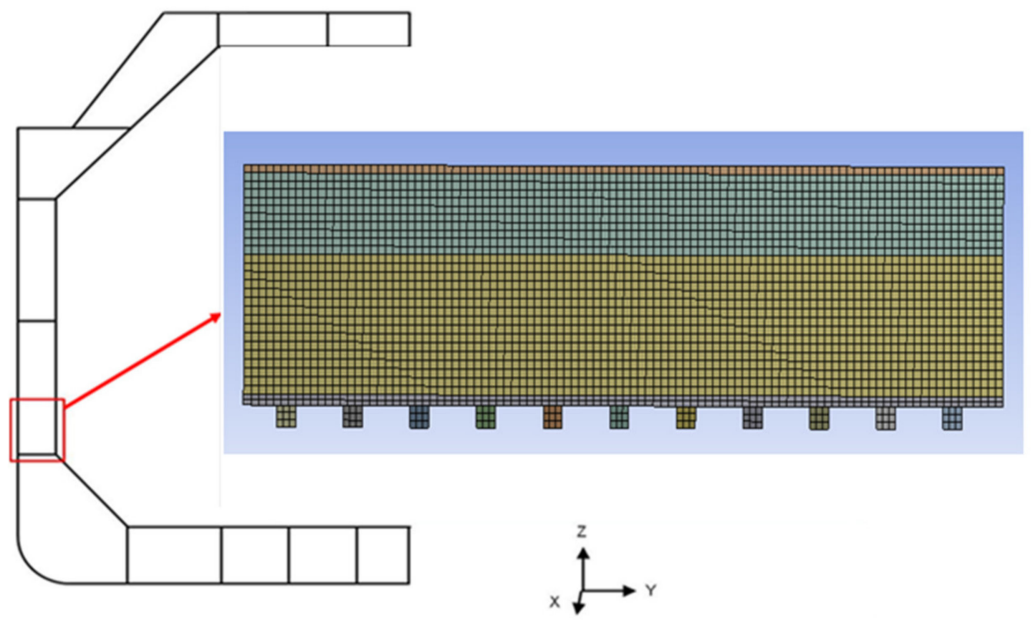

Figure 12. FE model of a Mark III insulation panel.

The boundary conditions of the FE model for structural analysis are that the bottom side of the mastic support is fixed, and symmetry is applied to the side surfaces of the CCS. Moreover, to match the insulation box of Mark III containment, a unit section of the insulation box is selected from the side shell of LNG vessels. Then an LNG CCS assembled from plywood, R-PUF, and mastic is modeled as shown in Figure 12. For the FE model of the insulation box, the mastic and R-PUF were assumed to be isotropic materials and the plywood was assumed to be an orthotropic material. 


\subsection{Impact Velocity of Sloshing}

For application of the localized FSI analysis method at the maximum pressure time in model test simulation, the maximum velocity of fluid obtained is assumed to give the maximum pressure on the insulation panel. Figure 13 shows the vectors of fluid velocity at $5.75148 \mathrm{~s}$. The maximum velocity obtained by CFD was scaled up by Froude's law, Equation (12). The fluid velocity calculated from the numerical analysis of the experiment was $1.9 \mathrm{~m} / \mathrm{s}$, which corresponded to $13.4 \mathrm{~m} / \mathrm{s}$ as scaled-up by Froude's scale law. The scale parameter $(\lambda)$ used here is 50 , the scale of the model test.

$$
V_{f s}=\sqrt{\lambda} \times V_{m s}
$$

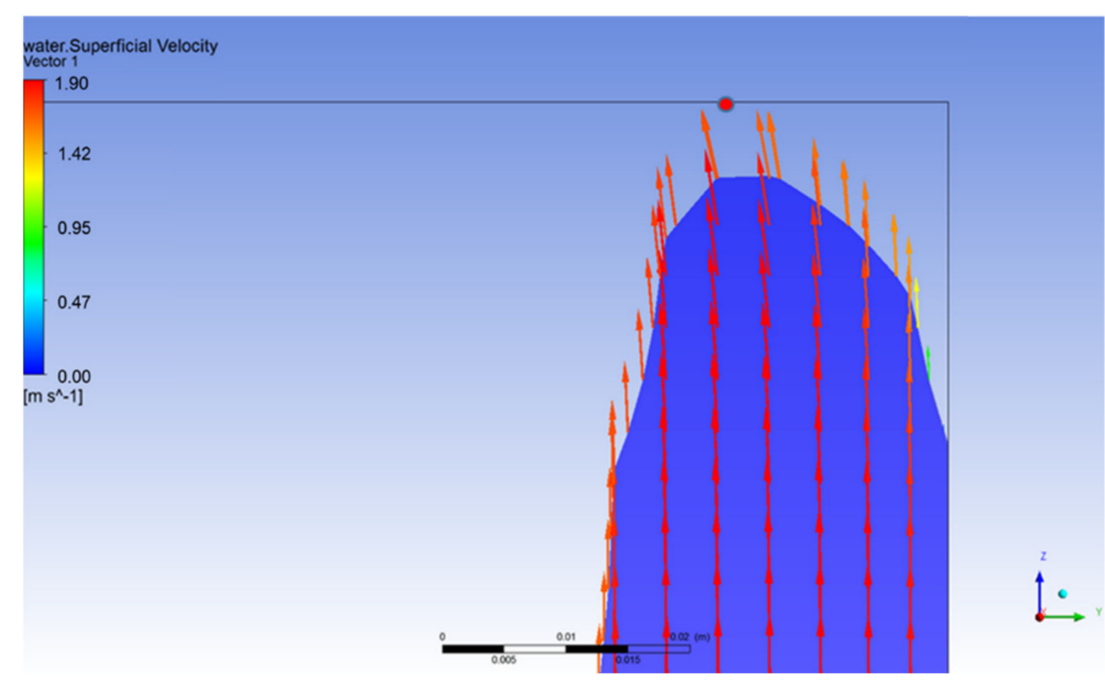

Figure 13. Vector plot of fluid velocity at $5.75148 \mathrm{~s}$.

\subsection{Localized Fluid Column Model}

The local impact analysis was carried out by FSI using a mesh deformation scheme and an FSI coupling interface. In the coupling analysis step, in order to evaluate the structural response caused by the fluid impact load, the interactive analysis performed repeatedly at each timestep by two-way FSI analysis scheme. The FSI model consists of both the structure and fluid domains as shown in Figure 14. The localized CFD model of a fluid column was coupled with the transient structural FE model of an insulation panel. When the maximum velocities of real scale were determined, a fluid column can be assumed to generate sloshing impact for hydro-elastic analysis. Therefore, the FSI between a fluid column and an insulation panel was considered. For the fluid column model, the height $(h)$ of fluid column is defined by fluid velocity $(V)$ and the rise time $(R T)$ that is defied by the maximum peak pressure signal as shown in Figure 9. The height $(h)$ of the column is defined by Equation (13).

$$
h=V \times R T
$$

For fully coupling the FSI analysis, the boundary conditions on the FSI interfaces are that the displacements of the fluid and solid domain are compatible and tractions at these boundaries must be in equilibrium. To create the FSI analysis conditions, the fluid-structure interface was applied to set the displacement $(u)$ at the nodes of the fluid region and solid region following Equation (14). Thus, the fluid and structure velocity at the interface behave identically. The stress term due to the hydro force is transferred to the solid region and structural analysis can proceed using Equation (15).

$$
u_{\text {fluid }}=u_{\text {solid }}
$$




$$
\sigma_{\text {fluid }} \cdot \boldsymbol{n}_{\text {fluid }}=\sigma_{\text {solid }} \cdot \boldsymbol{n}_{\text {solid }}
$$

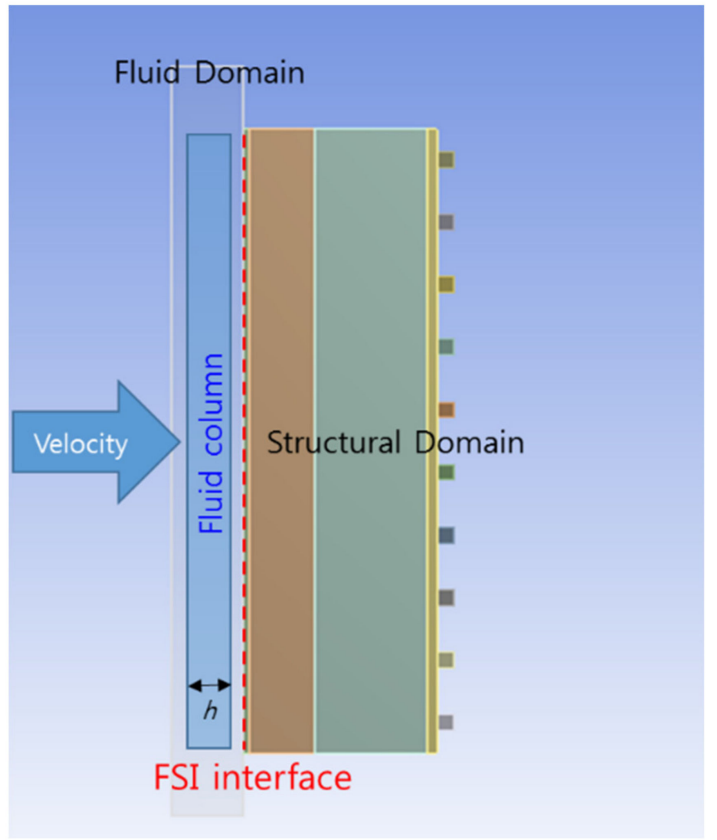

(a)

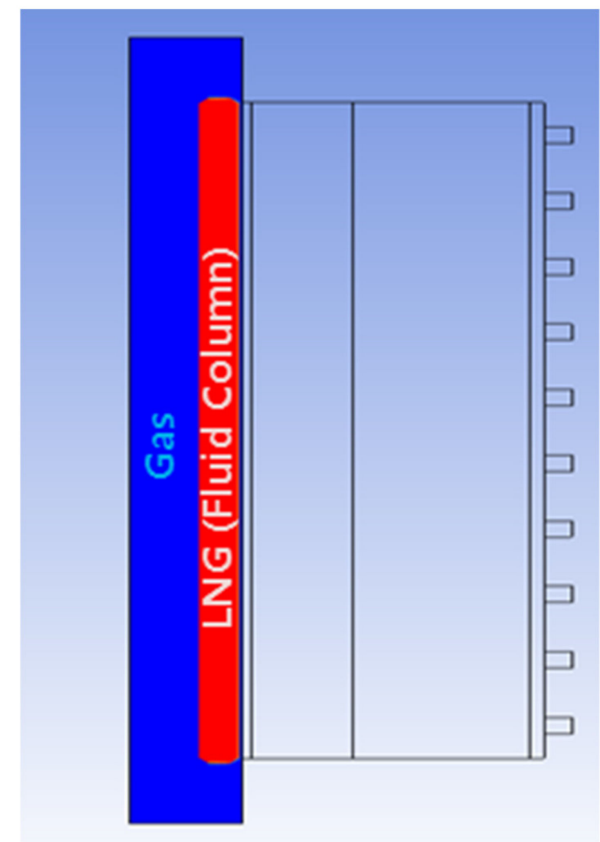

(b)

Figure 14. Local FSI model using a fluid column: (a) schematic configuration of the FSI model; (b) volume fraction of the multi-phase in fluid domain.

\section{Structural Strength Assessment of the LNG CCS}

This study has been carried out to confirm that the use of the suggested method with appropriate parameters for the sloshing assessment provides an effective method of investigating LNG CCS design. Figure 15 shows the fluid motion and volume fraction of the fluid column at impact time in the FSI analysis. In Figure 15, the red region is the volume fraction of the LNG fluid column, and the blue indicates the volume fraction of the gas region. The fluid column shows the process of impact and diffusion over time. The fluid column uniformly impacts the interface. The maximum pressure induced by the fluid column model is approximately $0.8 \mathrm{MPa}$ with a duration of $0.0067 \mathrm{~s}$, as shown in Figure 16. The pressure history shows that after the maximum pressure is generated, the subsequent pressure due to the fluid force is generated. Therefore, sloshing fluid flow modeled as incompressible fluids present a need for a compressible flow model for fluid and gas. This is possible since the CFD approach allows us to specify an order that satisfies the dynamic behavior. When calculating the structural response of Mark III CCS by the FSI model, the results for each timestep are shown in Figure 17. The maximum equivalent stress occurred in the mastic member connected with the hull, with a maximum of about $3.3 \mathrm{MPa}$ and a maximum deformation of about $2.6 \mathrm{~mm}$. In addition, the results were compared with the structural safety review criteria presented in the ABS guidance to verify the structural safety of the Mark III LNG CCS applied through the FSI analysis results. According to the guidance, the structural safety reviews of LNG CCS are evaluated by each structural member: plywood, R-PUF, and mastic [6]. Table 1 summarizes the maximum structural response for each member calculated through FSI analysis. In addition, the values shown in bracket " () " in Table 1 are the safety reference values for each member presented in ABS guidance. The results showed that all of the calculated results met safety standards. 


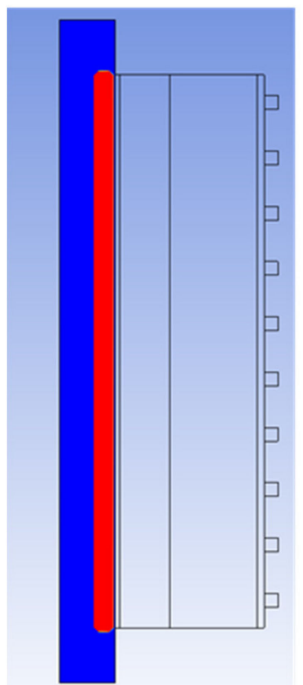

(a) $0.001 \mathrm{~s}$

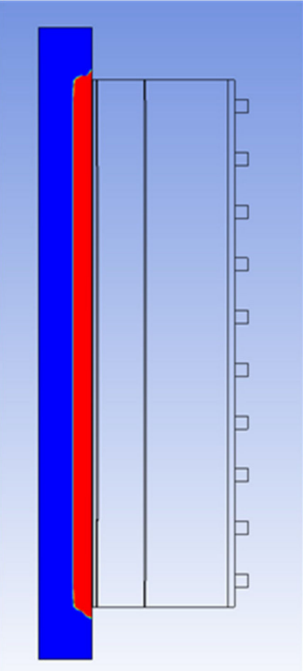

(d) $0.008 \mathrm{~s}$

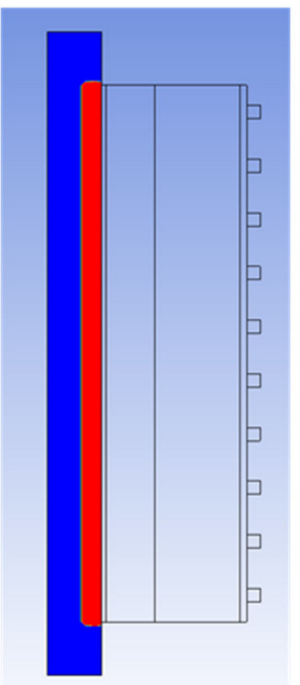

(b) $0.002 \mathrm{~s}$

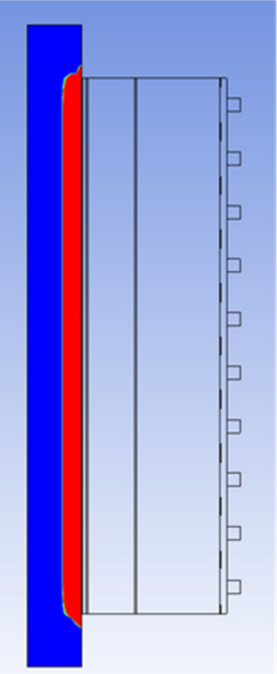

(e) $0.01 \mathrm{~s}$

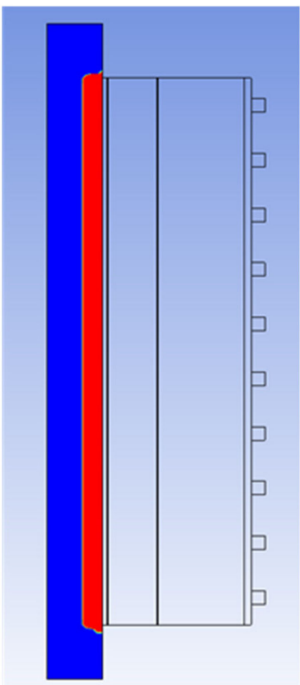

(c) $0.005 \mathrm{~s}$

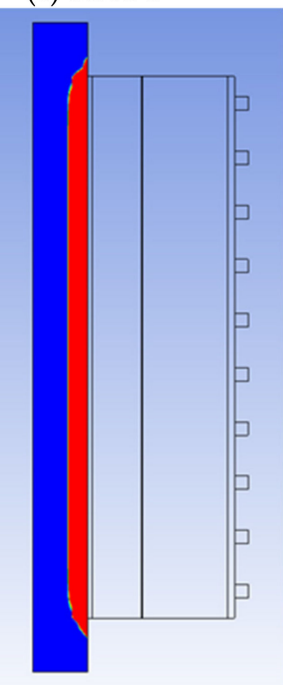

(f) $0.015 \mathrm{~s}$

Figure 15. Local FSI model using a fluid column: (a) at $0.001 \mathrm{~s} ;(\mathbf{b})$ at $0.002 \mathrm{~s} ;$ (c) at $0.005 \mathrm{~s}$; (d) at $0.008 \mathrm{~s} ;(\mathbf{e})$ at $0.01 \mathrm{~s} ;(\mathbf{f}) 0.015 \mathrm{~s}$.

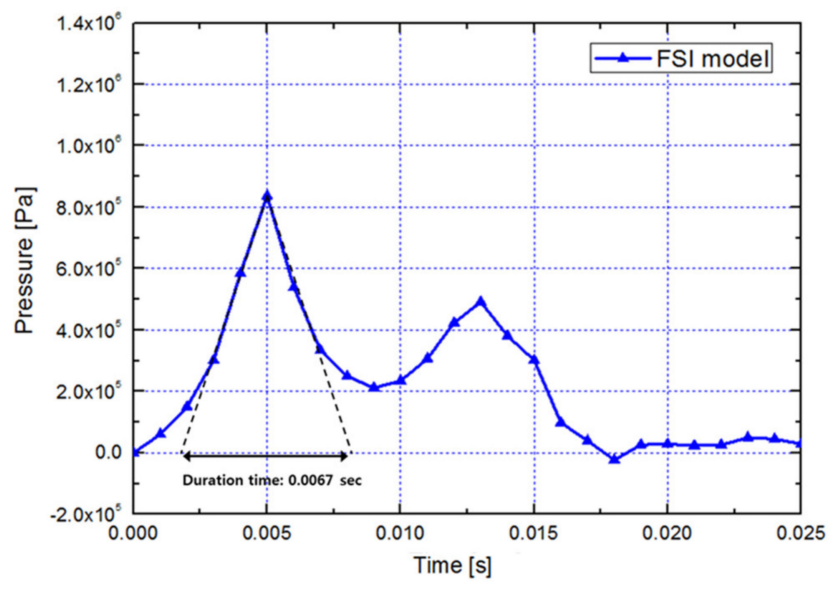

Figure 16. Max. pressure history from the fluid column model. 


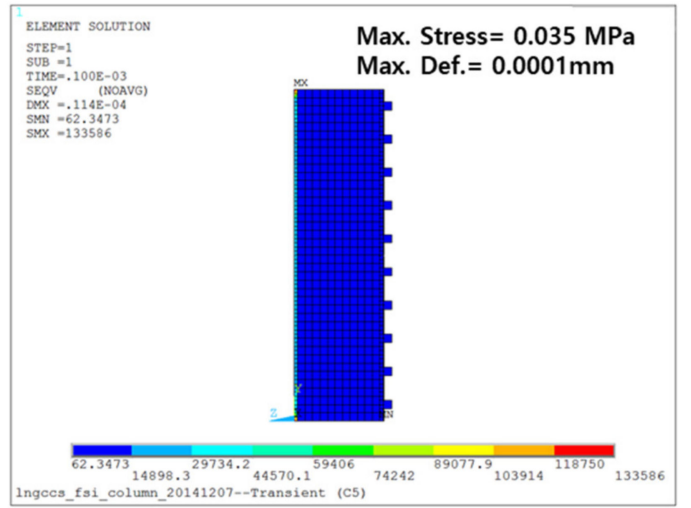

(a) $0.001 \mathrm{~s}$

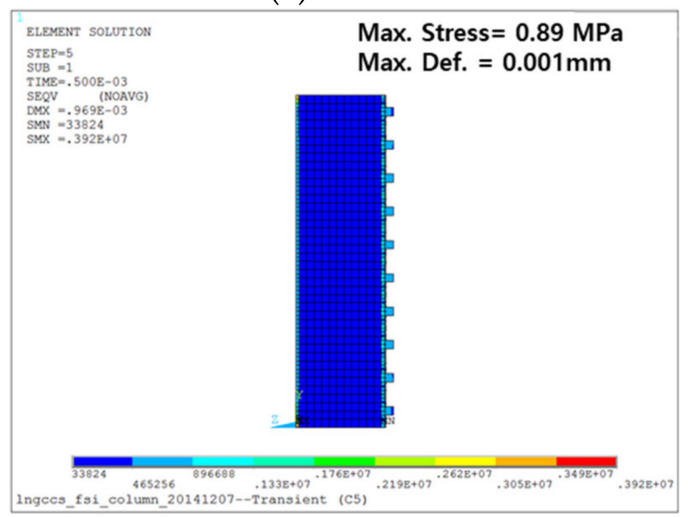

(c) $0.005 \mathrm{~s}$

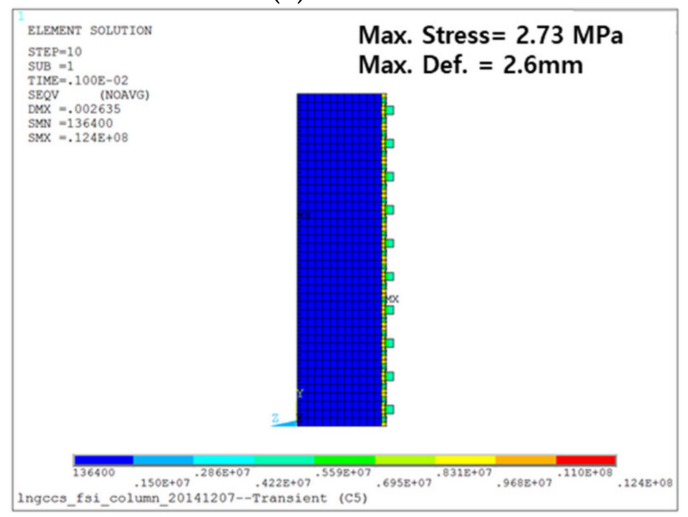

(e) $0.010 \mathrm{~s}$

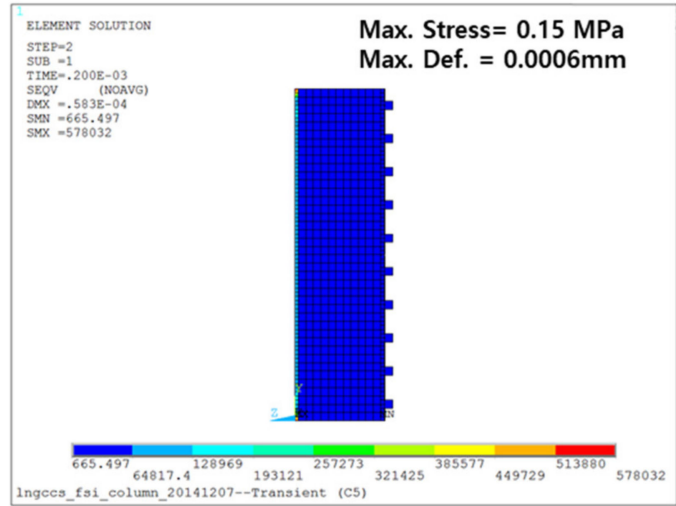

(b) $0.002 \mathrm{~s}$

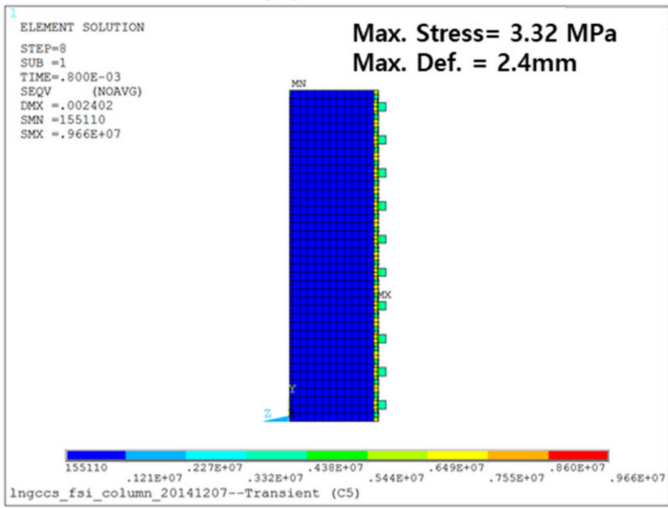

(d) $0.008 \mathrm{~s}$

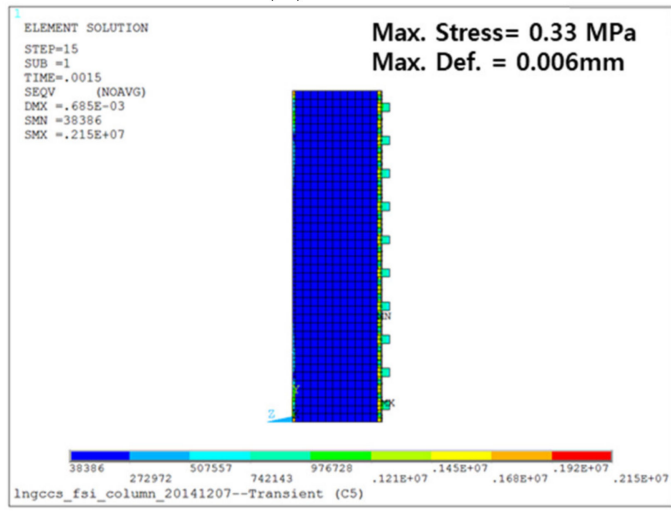

(f) $0.015 \mathrm{~s}$

Figure 17. Von-Mises stress distribution and max deformation in CCS: (a) at $0.001 \mathrm{~s}$; (b) $0.002 \mathrm{~s}$; (c) $0.005 \mathrm{~s}$; (d) $0.008 \mathrm{~s}$; (e) $0.010 \mathrm{~s}$; (f) $0.015 \mathrm{~s}$.

Table 1. Structural responses review of Mark III CCS by ABS guidance [6].

\begin{tabular}{cccccc}
\hline \multicolumn{5}{c}{ Max. Stress [MPa] } & $\begin{array}{c}\text { Max. } \\
\text { Deformation } \\
{[\mathbf{m m}]}\end{array}$ \\
\hline Whole CCS & 3.32 & Horizontal & Vertical & Shear & $\begin{array}{c}\text { Equivalent } \\
\text { Plywood }\end{array}$ \\
R-PUF & 0.8 & - & - & - & \\
Mastic & $1.69(15)$ & $0.26(40)$ & $1.21(2)$ & $1.32(2.8)$ & \\
\hline
\end{tabular}

Although a simple LNG CCS model was applied to calculate the structural response by the FSI analysis, the validity of the strength evaluation process of LNG CCS was reviewed using the proposed FSI model. 


\section{Conclusions}

In this paper we discuss using an inhomogeneous fluid and localized FSI model as a structural strength assessment model by sloshing with multi-phase CFD model based on the Eulerian-Eulerian approach. A typical strength evaluation method is difficult to consider the interaction between fluid and structure deformation since the slosh pressure is first obtained, and then structural analysis is performed by simplifying the sloshing pressure. Sloshing impact loads are affected by compressible viscous conditions of fluid model at the moment of fluid impact. Therefore, the suggested FSI analysis methods in this study for the hydro-elastic effects of sloshing phenomena and structural strength evaluations were also considered. To reflect the effect of the sloshing fluid impact on structural strength, the physical properties of the sloshing fluid flow were investigated. The buoyancy and drag forces acting on the gas phase are considered for the transfer of phase momentum between the multi-phases and are used to evaluate the structural strength of membrane type CCS of LNG vessels. The numerical scheme contains the multi-phase characteristics of the sloshing flow. The proposed scheme was validated by comparison with the results of the dam breaking problem and the rectangular sloshing model test. We also found that the local fluid column model is an efficient model that reduces the computational time for FSI analysis without compromising accuracy. Structural strength evaluation of CCS by sloshing flows was performed by the proposed FSI analysis. The results of structural response analysis of Mark III type CCS were discussed and the effectiveness of the structural response evaluation model by sloshing was reviewed. The proposed FSI model is considering multi-phase sloshing flows to evaluate the strength of CCS under the sloshing conditions, but more specific research should be conducted since it was applied to a simple model.

Author Contributions: Conceptualization and methodology, S.-Y.H. and J.-H.L.; validation, formal analysis, investigation, data curation, S.-Y.H.; project administration and funding acquisition, J.-H.L. Both authors have read and agreed to the published version of the manuscript.

Funding: This research was funded Korea Evaluation Institute of Industrial Technology (KEIT) grant funded by the Korea Government (MOTIE) (No. 20013102, Core Technology Development of Heat Loss Minimization in Liquid Hydrogen Tank for Ship).

Institutional Review Board Statement: Not applicable.

Informed Consent Statement: Not applicable.

Data Availability Statement: Not applicable.

Acknowledgments: This research was partially supported by the Korea Institute for Advancement of Technology (KIAT) (P0001968, HRD Program for Industrial Innovation), and by Korea Evaluation Institute of Industrial Technology (KEIT) (No. 20013102, Core Technology Development of Heat Loss Minimization in Liquid Hydrogen Tank for Ship) grant funded by the Korea Government (MOTIE).

Conflicts of Interest: The authors declare no conflict of interest.

\section{References}

1. Wang, W.; Peng, Y.; Zhou, Y.; Zhang, Q. Liquid sloshing in partly-filled laterally-excited cylindrical tanks equipped with multi baffles. Appl. Ocean Res. 2016, 59, 543-563. [CrossRef]

2. Xue, M.; Lin, P. Numerical study of ring baffle effects on reducing violent liquid sloshing. Comput. Fluids 2011, 52, 116-129. [CrossRef]

3. Hasheminejad, S.M.; Mohammadi, M.M.; Jarrahi, M. Liquid sloshing in partly-filled laterally-excited circular tanks equipped with baffles. J. Fluids Struct. 2014, 44, 97-114. [CrossRef]

4. Wang, W.; Guo, Z.; Peng, Y.; Zhang, Q. A numerical study of the effects of the T-shaped baffles on liquid sloshing in horizontal elliptical tanks. Ocean Eng. 2016, 111, 543-568. [CrossRef]

5. Kim, H.; Parthasarathy, N.; Choi, Y.; Lee, Y. Reduction of sloshing effects in a rectangular tank through an air-trapping mechanism-A numerical study. J. Mech. Sci. Technol. 2018, 32, 1049-1056. [CrossRef]

6. ABS (American Bureau of Shipping). Guidance Notes on Strength Assessment of Membrane-Type LNG Containment Systems under Sloshing Loads; American Bureau of Shipping: Houston, TX, USA, 2006. 
7. DNV (Det Norske Veritas). Sloshing Analysis of Lng Membrane Tanks; Classification Notes No. 30.9; DNV (Det Norske Veritas): Høvik, Norway, 2016.

8. BV (Bureau Veritas). Strength assessment of LNG membrane tanks under sloshing loads. In Guidance Note NI 564 DT R00 E; BV (Bureau Veritas): Neuilly sur Seine, France, 2011.

9. Graczyk, M.; Moan, T. Structural response to sloshing excitation in membrane LNG tank. J. Offsh. Mech. Arct. Eng. 2011, 133, 021103. [CrossRef]

10. Kim, Y. Numerical simulation of sloshing flows with impact load. Appl. Ocean Res. 2001, 23, 53-62. [CrossRef]

11. Faltinsen, O.M.; Rognebakke, O.F.; Lukovsky, I.A.; Timokha, A.N. Multidimensional modal analysis of nonlinear sloshing in a rectangular tank with finite water depth. J. Fluid Mech. 2000, 407, 201-234. [CrossRef]

12. Hwang, S.Y.; Lee, J.H.; Kim, S.C. Simplified impinging jet model for practical sloshing assessment of LNG cargo containment. In Proceedings of the 22nd International Offshore and Polar Engineering Conference, Rhodes, Greece, 17-22 June 2012; Volume 3, pp. 518-524.

13. Ito, H.; Suh, Y.S.; Chun, S.E.; Kumar, Y.V.S.; Ha, M.K.; Park, J.J.; Yu, H.C.; Wang, B. A direct assessment approach for structural strength evaluation of cargo containment system under sloshing enside LNGC tanks based on fluid structure interaction. In Proceedings of the 27th International Conference on Offshore Mechanics and Arctic Engineering, Estoril, Portugal, 15-20 June 2008; Volume 5, pp. 835-845.

14. Kim, Y.I.; Jang, C.H.; Kang, J.K. Development of the response-based strength assessment procedure of the LNG cargo containment system under sloshing impact load. In Proceedings of the 12th International Offshore and Polar Engineering Conference, Maui, HI, USA, 19-24 June 2011; Volume 3, pp. 170-176.

15. Kim, Y.; Lee, J.; Lee, Y.B.; Kim, Y.S. Sensitivity study on computational parameters for the prediction of slosh-induced impact pressures. In Proceedings of the 15th International Offshore and Polar Engineering Conference, Seoul, Korea, 19-24 June 2005; pp. 254-261.

16. Godderidge, B.; Turnock, S.; Earl, C.; Tan, M. The effect of fluid compressibility on the simulation of sloshing impacts. J. Ocean Eng. 2009, 36, 578-587. [CrossRef]

17. Ishii, M.; Hibiki, T. Thermo-Fluid Dynamics of Two-Phase Flow; Springer: New York, NY, USA, 2006.

18. Chen, B.; Nokes, R. Time-independent finite difference analysis of fully non-linear and viscous fluid sloshing in a rectangular tank. J. Comput. Phys. 2005, 209, 47-81. [CrossRef]

19. Wu, C.; Chen, B.; Hung, T. Hydrodynamic forces induced by transient sloshing in a 3D rectangular tank due to oblique horizontal excitation. Comput. Math. Appl. 2013, 65, 1163-1186. [CrossRef]

20. Arafa, M. Finite element analysis of sloshing in liquid-filled containers. J. Vib. Control 2007, 13, 883-903. [CrossRef]

21. Firoozkoohi, R.; Faltinsen, O.M. Experimental and numerical investigation of the effect of swash bulkhead on sloshing. In Proceedings of the 20th International Offshore and Polar Engineering Conference, Beijing, China, 20-25 June 2010.

22. Godderidge, B.; Tan, M.; Turnock, S.; Earl, C. A verification and validation study of the application of computational fluid dynamics to the modelling of lateral sloshing. In Ship Science Report No. 140; University of Southampton Fluid Structure Interaction Research Group: Southampton, UK, 2006.

23. Godderidge, B.; Turnock, S.; Tan, M.; Earl, C. An investigation of multiphase CFD modelling of a lateral sloshing tank. Comput. Fluids 2009, 38, 183-193. [CrossRef]

24. ANSYS. CFX Solver Theory Guide; Release 15; ANSYS, Inc.: Canonsburg, PA, USA, 2013.

25. Yang, K.K.; Kim, Y.H. Numerical Analysis of Violent Sloshing Problems by CCUP Method. J. Soc. Nav. Archit. Korea 2010, 17, 1-10. [CrossRef]

26. Hu, C.; Kashiwagi, M. A CIP-based method for numerical simulations of violent free-surface flows. J. Mar. Sci. Technol. 2004, 9, 143-157. [CrossRef]

27. Aliabadi, S.; Johnson, A.; Abedi, J. Comparison of finite element and pendulum models for simulation of sloshing. Comput. Fluids 2003, 32, 535-545. [CrossRef]

28. Gerber, A.G. Inhomogeneous multiphase model for nonequilibrium phase transition and droplet dynamics. In Proceedings of the ASME Joint US European Fluids Engineering Summer Meeting FEDSM, Miami, FL, USA, 17-20 July $2006 ;$ p. 12.

29. Gaztransport Technigaz-GTT Mark III Systems. Available online: https://gtt.fr/technologies/markiii-systems/ (accessed on 30 July 2021). 